\title{
Variations in Types of First-Cousin Marriages over a Two-Generation Period among Arabs in Israel
}

\author{
Rajech Sharkia1,2*, Muhammad Mahajnah ${ }^{3,4}$, Muhammad Athamna1, \\ Ahmad Sheikh-Muhammad5, Abdelnaser Zalan1 \\ ${ }^{1}$ The Triangle Regional Research and Development Center, Kfar-Qari', Israel \\ ${ }^{2}$ Beit-Berl Academic College, Beit-Berl 44905, Israel \\ ${ }^{3}$ Child Neurology and Development Center, Hillel-Yaffe Medical Center, Hadera, Israel \\ ${ }^{4}$ Ruth and Bruce Rappaport Faculty of Medicine, Haifa, Israel \\ ${ }^{5}$ The Galilee Society-The Arabs National Society for Research and Health Services, Shefa-Amr, Israel \\ Email: ${ }^{*}$ rajachsharkia@hotmail.com, ${ }^{*}$ rajach.sharkia@beitberl.ac.il
}

Received 20 August 2015; accepted 22 September 2015; published 25 September 2015

Copyright (C) 2015 by authors and Scientific Research Publishing Inc.

This work is licensed under the Creative Commons Attribution International License (CC BY).

http://creativecommons.org/licenses/by/4.0/

(c) (i) Open Access

\begin{abstract}
The consanguineous marriage phenomenon, particularly the first-cousin marriage type, had been common among different Arab societies and it was even regarded as integral to their culture. The purpose of our study was to determine the prevalence and trends of first-cousin marriage types over a period of two generations among Arab society in Israel. A specially designed questionnaire was used to survey the study sample that represented this society, and a comparative analysis was performed. During the two generations, the prevalence of first-cousin marriage types was found to be decreasing but still was most predominant among the various consanguineous marriage types. Among the first-cousin marriage types, the paternal subtype was reported to be the favored one in the two generations. Our study concluded that first-cousin marriage was still the preferable type in the Arab community of Israel.
\end{abstract}

\section{Keywords}

Arab Community in Israel, Consanguinity, First-Cousin Marriages

${ }^{*}$ Corresponding author.

How to cite this paper: Sharkia, R., Mahajnah, M., Athamna, M., Sheikh-Muhammad, A., \& Zalan, A. (2015). Variations in Types of First-Cousin Marriages over a Two-Generation Period among Arabs in Israel. Advances in Anthropology, 5, 171-176. http://dx.doi.org/10.4236/aa.2015.54016 


\section{Introduction}

Consanguineous marriages have been known throughout human history in various ancient societies. Over a thousand years ago, Arabs practiced these types of marriages, and it was even regarded as integral to their culture. The prevalence of consanguineous marriages was considered to be very low in the western world as compared to that in the Arab countries (Bittles, 2001; Hamamy, 2012).

Various types of first-cousin marriages are popular in Arab countries, accounting for approximately 20\% $50 \%$ of all marriages (Teebi, 2010). In Oman, the prevalence of consanguineous marriage was found to be very high (55\%); first-cousin unions were the most common type, constituting $24.1 \%$ of all marriages (Rajab \& Patton, 2000). Furthermore, another study in the same country also found a high prevalence of consanguinity (52\%), and first-cousin marriages were found to be $39 \%$ of all marriages (Islam, 2012). In a recent study in Tunisia, first-cousin marriages were found to be the most common type of consanguineous marriages and accounted for $31.8 \%$ of the overall sample studied, but they constituted $55.5 \%$ of all consanguineous unions (Halim et al., 2013). A study in Bahrain confirms that over a ten-year period first-cousin marriage rates have declined from 24\% to nearly 7\% (Al-Arrayed \& Hamamy, 2012). On the other hand, some studies noted varying results regarding maternal and paternal first-cousin marriages, ranging from 59.9\% of first-cousin unions in Lebanon (Khlat, 1988) to $73.3 \%$ in the UAE (Al-Gazali et al., 1997). The prevalence of maternal first-cousin marriages varies significantly among populations, with the lowest rates in urban Lebanon (Khlat, 1988) and the highest in lower income, rural and Bedouin tribal communities (Khlat et al., 1986; Radovanovic et al., 1999; Raz \& Atar, 2004). A study in Iran revealed that the rate of first-cousin marriage was about 28\% (Saadat, Ansari-Lari, \& Farhud, 2004). One of the latest studies found that the prevalence of first-cousin and closer marriage types was found to be about 22\% of the total marriages in Afghanistan (Saadat \& Tajbakhsh, 2012).

Similar to other Arab societies, the Israeli Arab community is known to have a high frequency of consanguineous marriages and has preferred the first-cousin marriage type (Sharkia et al., 2010; Sharkia et al., 2008). Despite the presence of many studies that have investigated consanguinity in the Israeli Arab community, to the best of our knowledge, no previous study has been conducted for exploring the prevalence and trends of the first-cousin marriage types of two generations over a long period of time. Therefore, this study has been designed to pursue this objective.

\section{Methods}

This present cross-sectional study was carried out in 2009. For sampling, a multistage design was used. The sample of our study (3173 marriages) was divided into two generations according to time period in which the marriage occurred: generation 1 from 1948 to1979, generation 2 from 1980 to 2009. Questionnaires were completed through face-to-face interviews with at least one of the couples. The fieldwork team was recruited from a group of field experienced surveyors. A training course was conducted for these surveyors by the supervisors and the project administrators.

Information on consanguinity between the couples was obtained through the interviews. Relationships were grouped into two major categories: consanguineous and non-consanguineous marriages, defined as follows:

A) Consanguineous marriages: This group includes two main categories namely, first-cousin and closer (i.e., double first-cousin and first-cousin marriages) and other consanguineous marriages. Furthermore, in order to investigate the frequencies and trends in the various first-cousin marriage types, subgroups of first-cousins marriages were also recorded. They included: paternal first cousins-PFC (parallel paternal first cousins-PPFC and cross paternal first cousins-CPFC) and maternal first cousins-MFC (parallel maternal first cousins-PMFC and cross maternal first cousins-CMFC) in which the couples are parallel or cross cousins of either patrilineal-PFC, or matrilateral-MFC, descent. Pedigree representations describing these sub-types of marriages were shown in Figure 1.

B) Non-consanguineous marriages; in which couples are not related.

From the genetic point of view, the mean inbreeding coefficients $(\alpha)$ were calculated.

The SPSS program was used for data management and descriptive statistical analysis.

\section{Results}

The total number of marriages contracted during the two generations was 872 and 2301 respectively (Table 1). The trend of consanguineous marriages was found to be significantly decreasing between the two generations, 

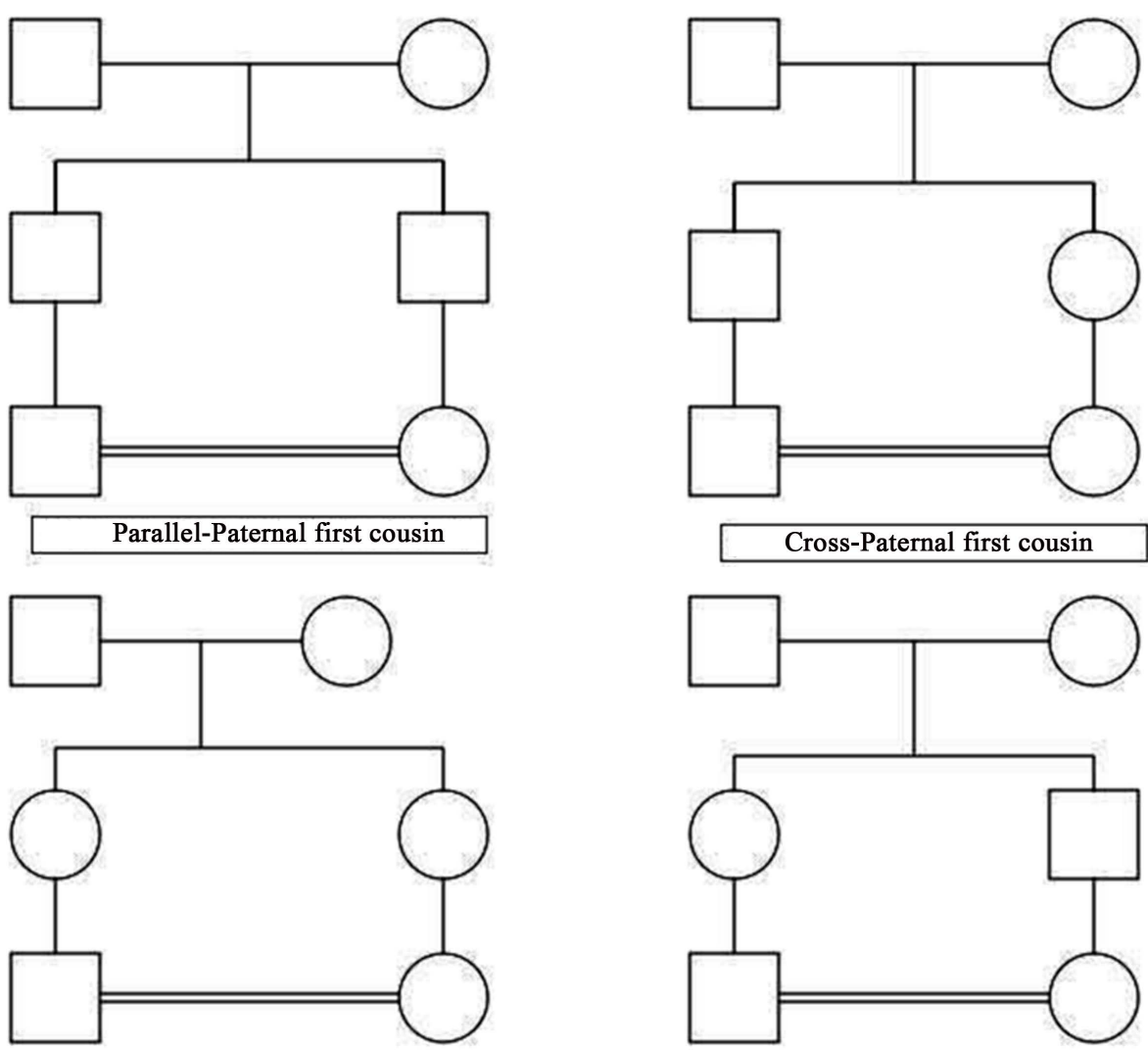

Parallel-Maternal first cousin

Cross-Maternal first cousin

\section{Figure 1. Pedigree of the various types of first-cousin marriages.}

Table 1. The prevalence of consanguineous and non-consanguineous marriages along with their mean inbreeding coeffincients $(\alpha)$ during two generations in the Arab society of Israel.

\begin{tabular}{|c|c|c|c|c|c|c|c|c|c|}
\hline \multirow{3}{*}{ Generation } & \multicolumn{6}{|c|}{ CONSA } & \multirow{3}{*}{$\begin{array}{c}\text { NON-CONSA } \\
\mathrm{N}\end{array}$} & \multirow{3}{*}{$\begin{array}{c}\text { TOTAL } \\
\mathrm{N}\end{array}$} & \multirow{3}{*}{$\alpha$} \\
\hline & \multicolumn{2}{|c|}{ FC and Closer } & \multicolumn{2}{|c|}{ Other Consa. } & \multicolumn{2}{|c|}{ Total Consa. } & & & \\
\hline & $\mathrm{N}$ & $\%$ & $\mathrm{~N}$ & $\%$ & $\mathrm{~N}$ & $\%$ & & & \\
\hline Generation-1 (1948-1979) & 201 & 23.1 & 175 & 20.0 & 376 & 43.1 & 496 & 872 & 0.01959 \\
\hline Generation-2 (1980-2009) & 375 & 16.3 & 400 & 17.4 & 775 & 33.7 & 1526 & 2301 & 0.01390 \\
\hline Total & 576 & 18.1 & 575 & 18.1 & 1151 & 36.3 & 2022 & 3173 & 0.01591 \\
\hline
\end{tabular}

CONSA: Consanguineous marriages; FC: First-cousin; N: Number; $\alpha$ : mean inbreeding coefficient.

from $43.1 \%$ to $33.7 \%$ ( $p=0.001)$. The prevalence of first-cousin and closer marriage types declined noticeably between the two generations (from $23.1 \%$ to $16.3 \%$ ). Additionally, the prevalence of the other consanguineous marriage types slowly declined from $20.0 \%$ to $17.4 \%$.

In order to determine the biological relatedness between the various consanguineous marriages in the two generations, the mean of inbreeding coefficients $(\alpha)$ for each generation was calculated and presented. It was declined significantly between the two generations from 0.01959 to $0.01390(p<0.05)$.

The first-cousin marriage types (FC) were clarified by the pedigree presented in Figure 1. The total number of paternal first-cousin (PFC) marriages in the two generations was found to be 330, and it accounted for $64.8 \%$ of all FC marriage types (Table 2). The parallel-PFC (PPFC) marriage type was the predominant one in the two generations at $50.3 \%$, while the cross-PFC (CPFC) marriage type was much less popular at (14.5\%). The total 
Table 2. The frequency and rates of first-cousin (FC) marriage types in the Arab society of Israel during the two generations.

\begin{tabular}{|c|c|c|c|c|c|c|c|c|c|c|c|c|c|c|}
\hline \multirow{4}{*}{ Generation } & \multicolumn{12}{|c|}{ FC Marriage Types } & \multirow{3}{*}{\multicolumn{2}{|c|}{ Total }} \\
\hline & \multicolumn{6}{|c|}{ PFC } & \multicolumn{6}{|c|}{ MFC } & & \\
\hline & \multicolumn{2}{|c|}{ PPFC } & \multicolumn{2}{|c|}{ CPFC } & \multicolumn{2}{|c|}{ Total of PFC } & \multicolumn{2}{|c|}{ PMFC } & \multicolumn{2}{|c|}{$\mathrm{CMFC}$} & \multicolumn{2}{|c|}{ Total of MFC } & & \\
\hline & $\mathrm{N}$ & $\%$ & $\mathrm{~N}$ & $\%$ & $\mathrm{~N}$ & $\%$ & $\mathrm{~N}$ & $\%$ & $\mathrm{~N}$ & $\%$ & $\mathrm{~N}$ & $\%$ & $\mathrm{~N}$ & $(\%)$ \\
\hline $\begin{array}{l}\text { Generation-1 } \\
(1948-1979)\end{array}$ & 90 & 51.7 & 29 & 16.7 & 119 & 68.4 & 33 & 19 & 22 & 12.6 & 55 & 31.6 & 174 & 20 \\
\hline $\begin{array}{c}\text { Generation-2 } \\
(1980-2009)\end{array}$ & 166 & 49.6 & 45 & 13.4 & 211 & 63 & 68 & 20.3 & 56 & 16.7 & 124 & 37 & 335 & 14.6 \\
\hline Total & 256 & 50.3 & 74 & 14.5 & 330 & 64.8 & 101 & 19.8 & 78 & 15.4 & 179 & 35.2 & & 09 \\
\hline
\end{tabular}

FC: First-Cousin; PFC: Paternal First-Cousin; PPFC: Parallel Paternal First-Cousin; CPFC: Cross Paternal First-Cousin; MFC: Maternal First-Cousin; PMFC: Parallel Maternal First-Cousin; CMFC: Cross Maternal First-Cousin; PFC = PPFC + CPFC; MFC = PMFC + CMFC; N: Number.

number of maternal first-cousin (MFC) marriages in the two generations was found to be 179, and it accounted for $35.2 \%$ of all FC marriage types. The percentage of the parallel-MFC (PMFC) marriage type (19.9\%) was higher than the cross-MFC marriage type (15.4\%) in the two generations. The prevalence of the PFC marriage type declined between the two generations by $5.4 \%$. However, the prevalence of the MFC marriage type increased at a similar rate. Even though the FC marriage types were PFC or MFC, the parallel-subtype rates were almost constant between the two generations. While the cross-subtype rate in the PFC was declining, the MFC rate was simultaneously increasing.

\section{Discussion}

Our results demonstrated a decline in the frequencies of consanguineous marriages, and thus, the mean inbreeding coefficients $(\alpha)$ declined during the two generations.

A similar decline in the rate of consanguineous marriages was also reported in our previous research work conducted on four selected villages of the Israeli Arab community (Sharkia et al., 2008). Furthermore, other studies on Arab societies revealed a decline in the prevalence of consanguineous marriages e.g. in Jordan (Hamamy, Jamhawi, Al-Darawsheh, \& Ajlouni, 2005), in Kuwait (Radovanovic et al., 1999) and in Saudi Arabia (AlAbdulkareem \& Ballal, 1998). Despite these decreases in rates of consanguinity, their relative occurrences are still considered to be very high in these communities. However, some Arab societies still showed an increase in consanguinity, for example, in Qatar (Bener \& Alali, 2006), Yemen (Jurdi \& Saxena, 2003) and the UAE (AlGazali et al., 1997). Furthermore, a study in Tehran showed an increase in the consanguinity rate in marriages contracted after 1997. This had been attributed to a political event-the Islamic revolution, which had an effect on cultural practices (Akrami, Montazeri, Shomali, Heshmat, \& Larijani, 2009).

As was reported in our study, though the first-cousin and closer marriage type declined significantly between the two generations, it was still maintained as the most common consanguineous marriage type. The results obtained in this study are in accordance with other previous studies (Na'amnih et al., 2015; Sharkia et al., 2008). In a comparative study among three generations from Jordan, it was found that the first-cousin marriage rate also declined with time (Hamamy et al., 2005). Another study in Bahrain confirmed that over a ten-year period firstcousin marriage rates had declined from $24 \%$ to nearly $7 \%$ (Al-Arrayed \& Hamamy, 2012).

There are two patterns of first-cousin marriages that are preferred in different Arab societies, namely, paternal and maternal first cousins (PFC and MFC). The prevalence of paternal first-cousin marriages is affected by various socio-demographic and economic factors which can be illustrated by the lowest rates in urban Lebanon (Khlat, 1988), and the highest rates in lower income, rural and Bedouin tribal communities (Khlat et al., 1986; Radovanovic et al., 1999; Raz \& Atar, 2004). The paternal first-cousin marriage type was the most preferred type (of all first-cousin unions) in various Arab societies: in Lebanon 50\% (Khlat, 1988), Yemen 64\% (Ahmed Gunaid, Ali Hummad, \& Abdallah Tamim, 2004), Palestinians 68\% (Assaf \& Khawaja, 2009), Jordan 70\% (Khoury \& Massad, 1992) and UAE 77\% (Al-Gazali et al., 1997), while their respective complementary percentages were of the maternal first-cousin marriage type. In accordance with these studies from Arab popula- 
tions, our data demonstrated that the paternal first-cousin marriage type was also the one favored $(\sim 65 \%)$ of all the FC marriage types among the Arab society in Israel. This preferred type of consanguineous marriage might be explained by the desire of the brides' families to maintain the stability of the family, and retain the family's property, parental authority and social protection for women (Hamamy, 2012; Raz \& Atar, 2004). The different types of paternal first-cousin marriages are especially popular, in particular the paternal parallel type "Bint amm", i.e., between a man and his father's brother's daughter. "Bint amm" unions are favored culturally and socially and they are considered to be the usual or expected form of marriage for first cousins whether they have been reared in adjoining or separate households (Teebi, 2010). This was particularly true from our results' point of view as the rate of the parallel-PFC (PPFC) marriage type was the predominant one $(\sim 50 \%)$ out of all the FC marriage types during the two generations. Our results showed that while the PFC marriage type declined between the two generations, the MFC marriage type increased, which might be attributed to the elevated role of women in the society that had led to the involvement of mothers in decision-making in their families, regarding the weddings of their sons and daughters.

As this study has demonstrated, the Arab Israeli society still has a high rate of closely-related marriages. Its underutilization of genetic counseling services (Sharkia et al., 2015) makes it susceptible to various inherited disorders (Abumwais, 2012; Sharkia et al., 2013; Zlotogora et al., 2003). These inherited disorders have a major impact on the Arab community's socioeconomic and the community health status. Therefore, it is necessary to manage this issue. This could be done by implementation of awareness and health education programs, especially among the young, in order to seek a reduction in the negative outcomes of consanguinity.

\section{Conflict of Interests}

The authors declare that there is no conflict of interests.

\section{Acknowledgements}

This project was partially supported by the European Union, EU Partner for Peace and by the DFG trilateral project (Reference number SCHO 754/5-1). We wish to express our gratitude to them. We thank Eid Rohany for performing the statistical analysis and many thanks to the scientific director Dr. Ibrahim Yehya for his cooperation and extending various facilities of the Research and Development Center. We are grateful to the families who participated in this study.

\section{References}

Abumwais, J. Q. (2012). Etiology of Chronic Renal Failure in Jenin District, Palestine. Saudi Journal of Kidney Diseases and Transplantation, 23, 158-161.

Ahmed Gunaid, A., Ali Hummad, N., \& Abdallah Tamim, K. (2004). Consanguineous Marriage in the Capital City Sana'a, Yemen. Journal of biosocial science, 36, 111-121. http://dx.doi.org/10.1017/S0021932003006138

Akrami, S. M., Montazeri, V., Shomali, S. R., Heshmat, R., \& Larijani, B. (2009). Is There a Significant Trend in Prevalence of Consanguineous Marriage in Tehran? A Review of Three Generations. Journal of Genetic Counseling, 18, 82-86. http://dx.doi.org/10.1007/s10897-008-9191-y

Al-Abdulkareem, A. A., \& Ballal, S. G. (1998). Consanguineous Marriage in an Urban Area of Saudi Arabia: Rates and Adverse Health Effects on the Offspring. Journal of Community Health, 23, 75-83.

http://dx.doi.org/10.1023/A:1018727005707

Al-Arrayed, S., \& Hamamy, H. (2012). The Changing Profile of Consanguinity Rates in Bahrain, 1990-2009. Journal of Biosocial Science, 44, 313. http://dx.doi.org/10.1017/s0021932011000666

Al-Gazali, L., Bener, A., Abdulrazzaq, Y., Micallef, R., Al-Khayat, A., \& Gaber, T. (1997). Consanguineous Marriages in the United Arab Emirates. Journal of Biosocial Science, 29, 491-497. http://dx.doi.org/10.1017/S0021932097004914

Assaf, S., \& Khawaja, M. (2009). Consanguinity Trends and Correlates in the Palestinian Territories. Journal of Biosocial Science, 41, 107-124. http://dx.doi.org/10.1017/S0021932008002940

Bener, A., \& Alali, K. A. (2006). Consanguineous Marriage in a Newly Developed Country: The Qatari Population. Journal of Biosocial Science, 38, 239-246.

Bittles, A. (2001). Consanguinity and Its Relevance to Clinical Genetics. Clin Genet, 60, 89-98.

http://dx.doi.org/10.1034/j.1399-0004.2001.600201.x 
Halim, N. B., Bouafif, N. B. A., Romdhane, L., Atig, R. K. B., Chouchane, I., Bouyacoub, Y. et al. (2013). Consanguinity, Endogamy, and Genetic Disorders in Tunisia. Journal of Community Genetics, 4, 273-284.

Hamamy, H. (2012). Consanguineous Marriages: Preconception Consultation in Primary Health Care Settings. Journal of Community Genetics, 3, 185-192. http://dx.doi.org/10.1007/s12687-011-0072-y

Hamamy, H., Jamhawi, L., Al-Darawsheh, J., \& Ajlouni, K. (2005). Consanguineous Marriages in Jordan: Why Is the Rate Changing with Time? Clinical Genetics, 67, 511-516. http://dx.doi.org/10.1111/j.1399-0004.2005.00426.x

Islam, M. M. (2012). The Practice of Consanguineous Marriage in Oman: Prevalence, Trends and Determinants. Journal of Biosocial Science, 44, 571-594. http://dx.doi.org/10.1017/S0021932012000016

Jurdi, R., \& Saxena, P. C. (2003). The Prevalence and Correlates of Consanguineous Marriages in Yemen: Similarities and Contrasts with Other Arab Countries. Journal of Biosocial Science, 35, 1-13. http://dx.doi.org/10.1017/S0021932003000014

Khlat, M. (1988). Consanguineous Marriage and Reproduction in Beirut, Lebanon. American Journal of Human Genetics, 43 , 188-196.

Khlat, M., Halabi, S., Khudr, A., Der Kaloustian, V. M., Opitz, J. M., \& Reynolds, J. F. (1986). Perception of Consanguineous Marriages and Their Genetic Effects among a Sample of Couples from Beirut. American Journal of Medical Genetics, 25, 299-306. http://dx.doi.org/10.1002/ajmg.1320250215

Khoury, S. A., \& Massad, D. (1992). Consanguineous Marriage in Jordan. American Journal of Medical Genetics, 43, 769775. http://dx.doi.org/10.1002/ajmg.1320430502

Na'amnih, W., Romano-Zelekha, O., Kabaha, A., Rubin, L. P., Bilenko, N., Jaber, L., Honovich, M., \& Shohat, T. (2015). Continuous Decrease of Consanguineous Marriages among Arabs in Israel. American Journal of Human Biology, 27, 9498. http://dx.doi.org/10.1002/ajhb.22610

Radovanovic, Z., Shah, N., \& Behbehani, J. (1999). Prevalence and Social Correlates of Consanguinity in Kuwait. Annals of Saudi Medicine, 19, 206-210.

Rajab, A., \& Patton, M. (2000). Short Report: A Study of Consanguinity in the Sultanate of Oman. Annals of Human Biology, 27, 321-326. http://dx.doi.org/10.1080/030144600282208

Raz, A. E., \& Atar, M. (2004). Cousin Marriage and Premarital Carrier Matching in a Bedouin Community in Israel: Attitudes, Service Development and Educational Intervention. Journal of Family Planning and Reproductive Health Care, 30 , 49-51. http://dx.doi.org/10.1783/147118904322701992

Saadat, M., \& Tajbakhsh, K. (2012). Prevalence of Consanguineous Marriages in West and South of Afghanistan. Journal of Biosocial Science, 1, 1-7.

Saadat, M., Ansari-Lari, M., \& Farhud, D. (2004). Short Report Consanguineous Marriage in Iran. Annals of Human Biology, 31, 263-269. http://dx.doi.org/10.1080/03014460310001652211

Sharkia, R., Azem, A., Kaiyal, Q., Zelnik, N., \& Mahajnah, M. (2010). Mental Retardation and Consanguinity in a Selected Region of the Israeli Arab Community. Central European Journal of Medicine, 5, 91-96.

Sharkia, R., Mahajnah, M., Zalan, A., Athamna, M., Azem, A., Badarneh, K., \& Faris, F. (2013). Comparative Screening of FMF Mutations in Various Communities of the Israeli Society. European Journal of Medical Genetics, 56, 351-355. http://dx.doi.org/10.1016/j.ejmg.2013.04.002

Sharkia, R., Tarabeia, J., Zalan, A., Atamany, E., Athamna, M., \& Allon-Shalev, S. (2015). Factors Affecting the Utilization of Genetic Counseling Services among Israeli Arab Women. Prenatal Diagnosis, 35, 370-375. http://dx.doi.org/10.1002/pd.4550

Sharkia, R., Zaid, M., Athamna, A., Cohen, D., Azem, A., \& Zalan, A. (2008). The Changing Pattern of Consanguinity in a Selected Region of the Israeli Arab Community. American Journal of Human Biology, 20, $72-77$. http://dx.doi.org/10.1002/ajhb.20678

Teebi, A. S. (2010). Genetic Disorders among Arab Populations. Berlin: Springer Science \& Business Media. http://dx.doi.org/10.1007/978-3-642-05080-0

Zlotogora, J., Leventhal, A., \& Amitai, Y. (2003). The Impact of Congenital Malformations and Mendelian Diseases on Infant Mortality in Israel. Israel Medical Association Journal, 5, 416-418. 